\title{
Response: Letter to the Editor: Thoughts on "Is advanced neuroimaging for neuroradiologists?" by S. Cocozza and the content of "Neuroradiology" by Lars Arnim Rödiger
}

\author{
Rüdiger von Kummer ${ }^{1}$
}

Received: 1 February 2017 / Accepted: 2 February 2017 / Published online: 1 March 2017

(C) Springer-Verlag Berlin Heidelberg 2017

Dear Dr. Rödiger,

Thank you for your comments on the bibliometric analysis which has shown that over the last decade, professionals other than radiologists conducted the majority of studies in the field of advanced neuroimaging [1]. I appreciate your insight as a clinically active diagnostic neuroradiologist with some experience in neuroimaging research. I also understand your frustration at being involved as "junior partner" by non-medical scientists in such research and by the growing numbers of publications on advanced neuroimaging and neurointerventions that you feel are not relevant to your daily practice.

Imaging of the brain and its functions is of high interest for basic science neuroscientists as well as for clinical neuroradiologists. In an ideal environment, both specialists work closely in tandem and help each other understand the brain's functions and its disorders. Neuroradiology publishes articles supporting a better understanding of central nervous system physiology and pathophysiology. It is natural that the impact of seminal basic science articles such as "Computerized transverse axial scanning (tomography)," written by a physicist [2], or "MR imaging of intravoxel incoherent motions: application to diffusion and perfusion in neurologic disorders," written by a clinician and physicist [3], may not be immediately obvious to all readers. Neuroradiology will attempt to

Rüdiger von Kummer

Ruediger.vonkummer@uniklinikum-dresden.de

Institut und Poliklinik für Diagnostische und Interventionelle Neuroradiologie, Universitätsklinikum Carl Gustav Carus an der Technischen Universität Dresden, Fetscherstraße 74,

01307 Dresden, Germany further help its readers by maintaining an overview of the entire field of neurosciences with special emphasis on patient care.

I would respectfully disagree, however, that articles on neurointerventions should not be published in Neuroradiology. The different indications and techniques have a direct therapeutic impact and effect on clinical practice of non-interventional neuroradiologists. Neuroradiologists should know, for example, how best to diagnose patients with acute cerebral ischemia or follow up on patients with coiled aneurysms.

As a busy clinical neuroradiologist, I know that you do not have time to study all articles published in each issue. However, following your suggestions, we will endeavor to guide readers like you better by publishing more state-ofthe art clinical articles. These will cover all sections our journal currently provides, including diagnostic and interventional.

Sincerely yours,

Prof. Dr. med. Rüdiger von Kummer

\section{References}

1. Cocozza S, Russo C, Pontillo G, Ugga L, Macera A, Cervo A et al (2016) Is advanced neuroimaging for neuroradiologists? A systematic review of the scientific literature of the last decade. Neuroradiology 58:1233-1239

2. Hounsfield GN (1973) Computerized transverse axial scanning (tomography). 1. Description of system. Br J Radiol 46:1016-1022

3. LeBihan D, Breton E, Lallemand D, Grenier P, Cabanis E, LavalJeanet M (1986) Mr imaging of intravoxel incoherent motions: application to diffusion and perfusion in neurologic disorders. Radiology 161:401-407 